\title{
Listening to 'the thick bunch': (mis)understanding and (mis)representation of young people in jobs without training in the South West of England
}

\begin{abstract}
Young people in jobs without training (JWT) are ubiquitous but invisible, working in shops, cafes, and other low-waged, low-status occupations. Commonly elided with young people who are not in education, employment or training (NEET), they are positioned as the 'thick bunch' with empty and meaningless working lives. The main purpose of the research was to explore the experiences of this group of marginalised and socially disadvantaged young people through a deeper understanding of their interests and enthusiasms inside and outside work. These young people have been (mis)understood and (mis)represented. A more holistic and nuanced approach that is not uncritically founded upon a set of neo-liberal stereotypes and assumptions and instead recognises the complexity of their lives, would offer new opportunities for understanding and representation of their interests. Our findings challenge the conflation of identity with work and the notion that only certain forms of employment create meaning.
\end{abstract}

Keywords: Young people; identity; work; stereotypes 


\section{Background and Context}

I have learned of the apparent importance of young people getting work, work without training doesn't necessarily mean a dead end for these young people, it appears to be a springboard...those whom I interviewed appeared to have a happier more independent view on life and all had aspirations. This is not always the case for NEET clients. (Personal Adviser journal)

There is an emerging body of research concerning young people in the NEET (not in education, employment or training), category (Yates and Payne 2006; Maguire and Rennison 2005; Bynner and Parsons 2002), yet little has yet been written about the lives and work patterns of young people who are in JWT, particularly from the perspectives of young people themselves. JWT is essentially a policy construct that has been defined by DfEE (1998) and by Anderson et al. for DfES (2006) as being employed for 16 hours a week or over, not being engaged in formal training which leads to a nationally accredited qualification at Level 2 and not having Level 2 qualifications.

Young people in JWT are both perceived as the 'thick bunch' by the media and in the policy literature as a marginalised and socially excluded deficit category, lacking both aspirations and prospects. Although employed rather than unemployed, they are perceived as a subset of young people who are NEET. The assumption is that they have low levels of functional literacy and numeracy skills, and a deficit of life and vocational skills and are feckless and lazy - hence the sobriquet 'dead-end kids in dead-end jobs' (Quinn et al. 2008a). Cole (2007), argues that many of the assumptions that have underpinned policy in this area are predicated on social-psychological theories of unemployment where work is assumed to be a primary source of identity and status, providing individuals with a shared experience and structure in which they organise their lives (Jahoda 1982).

The 'problem' of young people leaving school without formal qualifications and without high levels of functional literacy and numeracy is not a new phenomenon. Certainly in the 1950s and 1960s at a time of full employment many young people left school at age 15 without these functional skills yet managed to find employment and 
work. Youth unemployment only surfaced as a major issue in the 1970s as the oil crisis and global restructuring highlighted deeper structural problems in the economy. Since that time there has been a shift away from shop-floor and factory work to postFordist work environments where there has been an increased demand for skilled and flexible workers in manufacturing technology and services (Avis 1996). Notwithstanding this shift, the demand for labour in low-skill and low-paid jobs remains a persistent feature of the working environment (Aldridge and Tuckett 2007). Department of Trade and Industry figures released in 2007 show that 'there is a shortage of four million people to fill jobs that require no qualifications at all in sectors from service industries to manufacturing' (Nash 2007: 1). As we enter a period of recession there will be further shifts in these patterns of employment.

The response of the government has been to extend education and training opportunities for young people. This has been achieved through the expansion of the numbers of young people in the higher education and the further education sectors of the economy. Notwithstanding this expansion, the Leitch Review (2006) noted that the proportion of young people remaining in education in the UK is currently below the Organisation for Economic Cooperation and Development (OECD) average, which is far from the aspiration to benchmark against the upper quartile by 2020 (OECD 2006; 2007). In England, recent initiatives have included the requirement that young people participate in education/training to age 18 (DfES 2007). This is set alongside introduction of the 14/19 Diplomas ( Hayward et al. 2006; Hodgson and Spours 2007) which will provide formalised certification for young people.

A key assumption of the prevailing discourse is that there is a clear trajectory or ladder of progression which young people traverse until they reach their occupational goals. While this is true of a minority of young people it is indicative of a naive and simplistic view of the career trajectories of the majority of young people who often do not move in this way through their work careers (Lawy 2003; Furlong and Cartmel 1997; Goodwin and O'Connor 2007). Clearly the nature of transition has changed substantially since the 1970s, when Ashton and Field (1976) identified three fairly straightforward trajectories (careerless, short-term careers and extended careers) into work. Yet, there is an assumption, certainly in the policy literature, that young 
people's work careers would necessarily follow the kinds of linear patterns associated with their parents' and grandparents' generations.

Our research challenges many of the stereotypes and assumptions that underpin current policy claims and understandings. We suggest that young people have been (mis)understood and (mis)represented. We would not wish to suggest that young people in JWT are not in need of high quality workplace training, fair pay and job security; rather we would argue that what is needed is a more nuanced understanding of their lives and their interests which recognises and addresses the very real problems that they face.

\section{Methodology}

The basic assumption of our approach is that young people in JWT have had 'things done for them' with little or no consultation with them about their needs, interests or aspirations. Indeed, they have been targeted by policy which has been almost exclusively focused upon increasing their employability (Lawy et al. 2008). While we wanted the predominant focus of the research to be centred on the experiences, interests and understandings of young people as they moved through their JWT careers - and here we use the notion of career 'as a moving perspective in which the person sees his (sic) life as a whole and interprets the meaning of his various attributes, actions, and the things that happen to him' (Hughes 1937: 409-410) - we were also aware of the benefit of contextualising our qualitative data with available quantitative data from other sources.

One of the challenges of understanding the scale of the JWT category is that the various agencies that compile the statistical data do so on the basis of very different criteria. There is not yet a national database which tracks all young people as they move through and beyond school. Despite this lack of consistency, the data indicate that for the last ten years, up until the onset of the current recession (January 2009), the proportion of 16-18 year olds in the NEET category has remained remarkably stable at about $10 \%(200,000-300,000)$ of the total population of young people at any one time in England, Wales and Scotland (DfES 2006). The figures from ONS (2005a) and Connexions (2005) for 16/17 year olds in full-time education are broadly in accord with one another, with the numbers in fulltime education creeping up from a 
base of around 70\% participation to around 75\% in a nine year period between 1997 and 2006.

Our research (Quinn et al. 2008a) confirms that young people in JWT do tend to move into and out of the NEET category often as they move from one job to another. Consistency in the numbers of JWT masks a group that is fluid and in a continuous state of flux. Therefore, it is hardly surprising that young people in JWT who are at the 'softer' end of the spectrum have been targeted by policy. It seems unlikely that the government will be able to achieve its policy target of $2 \%$ of young people in NEET by 2010 (Nuffield, 2008) - indeed it seems likely that the numbers of young people in JWT and NEET will increase and so come under even more pressing scrutiny.

The research aimed to address four key research questions.

1. What are the characteristics of young people in JWT? How can these best be theorised and understood?

2. What are the interests and enthusiasms of young people in JWT?

3. How can Connexions services best understand and respond to these diverse interests of young people in JWT?

4. At what points in their careers and in what ways are young people in JWT most receptive to moving into learning opportunities?

One of the main problems we faced in operationalising the research was deciding which young people to actually focus upon. We were aware, for example, that the category is inclusive of young people taking a gap-year between school and university. In order to factor this group out of our study we chose to focus upon young people who had already been seen by Connexions for a year after leaving school. This left us with a sample that was generally less well qualified than those in the study undertaken by Huddleston and Maguire (2008) and often from families with fewer resources and less financial security.

A second issue that was important to us was that we wanted the research to be as participative as possible (see Quinn et al. 2006). In order to achieve this the research team from the University worked closely with a group of 11 (subsequently 10) 
Connexions Personal Advisers (PAs) from the six participating Connexions partnerships across the SW region. We organised three 'training days' based at the University of Exeter for the PAs, during the course of the project, where they were involved in developing the interview specifications for the telephone interviews as well as subsequent discussions about the data findings. The PAs were encouraged to keep journals where they reflected upon what they had learned through their engagement in the research. The PAs' work was critical in identifying the young people for the face-to-face interviews conducted by the university researcher and the telephone interviews which they conducted themselves. This capacity-building aspect was an important feature of our methodology. It afforded insights that we might otherwise have missed and provided an opportunity for the participating PAs to share their experiences and understandings with colleagues in the work-place.

We did not simply want to provide a snapshot of the lives of the young people but sought to provide some sense of the transitional and transformative quality by incorporating a longitudinal dimension into the research through a series of reinterviews (for example, Lawy 2006). The majority of the sample of the young people was 17-18 years old. The cohort was drawn from the counties of Cornwall, Devon, Somerset, Gloucestershire, Dorset and Wiltshire. The diversity of the cohort was represented by the fairly even gender split between males and females, although ethnic origins were almost wholly white, reflecting the predominantly rural demographic. The young people were involved in a range of part-time and full-time jobs in all the different sectors of the economy including manufacturing; retail and clerical; farming and gardening and leisure and tourism. The interviews followed the protocols used in the Connexions service and the ethical guidelines of the University, with the participants free to leave the project at any time.

The PAs conducted 100 first-round telephone interviews. However, the climate of uncertainty about the future of Connexions in combination with a not unexpected attrition rate meant that only 55 of the original sample were re-interviewed. 14 faceto-face interviews were conducted by a university researcher with 13 young people returning for a second interview. Securing face-to face interviews was more problematic in the first round. Often, young people failed to turn up, despite the fact that they were to be offered a small pecuniary reward for attending both interviews. 
By the time of the second interview the young people were easier to contact and engaged more enthusiastically with the process, having formed good relationships with the researcher and being gratified by her commitment to and interest in them. These interviews were semi-structured and focused around a number of key themes which included discussion of their background; experiences of work and school; training opportunities; aspirations for the future etc (see Quinn et al. 2008b). The interviews lasted between 45 minutes and 1 hour. They were tape-recorded and fully transcribed. A small focus group was held at a Connexions office in March 2007. We made extensive attempts to hold a subsequent focus group with a larger group of young people to include peer-led discussions about our interim findings. Although such an opportunity was arranged as part of a day event organised by Connexions, this event had to be cancelled as an insufficient number of young people agreed to participate, exemplifying the difficulty in sustaining contact with these 'hard-to-reach' young people.

Following the first round of interviews, a participative research seminar was held to discuss our findings with key stakeholders in the region including employers, government agencies and educational/training representatives. This was particularly useful since it provided the opportunity to triangulate the data and gave us an opportunity to refine some of our ideas about the conduct of the second stage of the research. We found that initially the stakeholders drew more upon negative stereotypes to describe the young people, such as 'trapped', 'dead-end',' fearful' 'less-qualified' but they also included descriptions such as 'flexible' and 'pragmatic.' In a later session, where we shared our findings from the interview transcripts, the stakeholders started to reconsider and reconstruct their views of the young people, so that, for example, there should be a 'fostering of positive narratives.' There was a recognition of the elision between young people in JWT and NEET and also that young people in these categories neither comprise a homogeneous group whose needs are necessarily identical with one another nor a group whose needs correspond to the often economistic claims of politicians and policy makers.

Although all of our interviews have a strong regional flavour, they are nonetheless representative of a broad area of the UK which encompasses the area between Cornwall and Gloucestershire and includes Wiltshire and Dorset. The quantitative 
trends, drawn from government statistics (ONS 2005, 2005a, 2006) and Connexions (2005) data, suggest only that the South West has a larger number of small firms employing around 11 employees and also does not sustain a large ethnically diverse and migratory population as other regions in the UK.

\section{Findings}

In an earlier paper (Quinn et al. 2008b) we presented some initial findings from our work. In this paper we draw upon our full findings from the research study (Quinn et al., 2008a) in order to exemplify some key issues that emerged from the data. Throughout the research we sought to explore the meanings and understandings of the young people - albeit from an outsiders' perspective (Weber 1964) - and represent their views in a way that was intelligible (see, Golby 1994) and which resonated with the realities of their everyday lives. This contrasts with the assumption that others, comprising policy makers, educationalists, careers advisers etc, are in a better position to represent the young people and make decisions on their behalf. We indicate below how this has led to a (mis)understanding and (mis)representation of their interests.

\section{(Mis)understanding}

When asked to provide an account of their lives many of our interviewees were reluctant or unable to do so. There are many reasons for this. In some cases they seemed almost embarrassed, perhaps because they were being asked to describe a situation where they had 'failed' when judged in society's terms; in other cases they were simply guarded about self-disclosure because of the possible implications. Then there were cases where the young people simply had not constructed a coherent narrative of themselves and their lives or to use the language of $\mathrm{C}$. Wright Mills (1940) a 'vocabulary of motive' to explain their actions. George was not untypical:

I lived in Swindon till I was 15 and then I moved away on my own ... down to Bournemouth and I lived with my girlfriend.

Did you go to school there?

No I went to work in a warehouse and got a supervisor's job there.

What, when you were 15? 
I got it when I was 16.

So did you stay on at your secondary school in Swindon to take your GCSEs or not?

I did GCSEs there. I was back and forth when I was in Bournemouth.

It was not that George was deliberately seeking to obfuscate, rather that narratives of the self (Giddens 1991) are a middle-class luxury that are not available to all (Ribbens-McCarthy et al. 2002; Skeggs 1997, 2004). This was emphasised when George was asked about his GCSE subjects and grades:

\section{What GCSE's did you do?}

English I got 2 Es - no that's Science I got 2 Es. I got English an E. Maths I did terrible. I got a D in Theatre Graphics and Design. Used to do Cooking but didn't actually take that but I could have done.

So in total how many did you get then?

That's a tough question. I wouldn't know.

GCSE grades are important for those individuals that are seeking to move into further or higher education however George had no such ambitions. As he said:

My whole thought of GCSE's was a waste of time cause I've not actually had to use them. Ever since I've left school, no one's asked me 'What grades have you got?'

Initially George had wanted to follow his father into a career as a mechanic but having failed to secure an apprenticeship he moved through a succession of part-time and temporary jobs. Eventually he settled upon a bar job. His was not an 'imagined future' (Ball et al. 1999) rather a future that was grounded in the here and now. Any assumption about young people in JWT being feckless and lazy certainly did not apply to George: 
I love working in bars most, it's something probably I am better at than anything. .. Well out of all the jobs I have been in the bar one is the one I've done best... I always used to dread working on a bar ... Well not on a bar but working with customers. Because the public being what they are, but working on a bar like how I was, and getting all the respect I was getting and all that.

George was not frightened of work or of the learning associated with it, rather the opposite he was keen to learn as he took great pride in all that he did. However, he wanted to learn though practical application rather than through book work.

They didn't want no trainees. You just go in, you train as you do the job. I thought that sounded good. I like doing that sort of work because studying I never got the hang of, cos textbooks and that, it doesn't really register in my brain that much.

I've learnt as I've gone along and when I was working at the warehouse I was just like loading up the trolleys, taking out gear, getting the order ready and bringing in stuff and they saw I was coping well and they offered me the job as the supervisor at night.

George's case was not untypical of the cohort that we interviewed. He was proud of the fact that he was achieving something tangible and that he was able to make a contribution. Indeed, many of the young people in our study demonstrated a commitment to work, and range of skills and attributes - often developed at home or in their leisure time rather than in school - which belied simple stereotyping. Much of the learning associated with these skills was neither immediately apparent nor formally accredited. The outstanding example was Rick who had turned an amateur interest in magic into what seemed to be a very promising career as a magician. Although Rick's case was not typical it does serve to emphasise the range of skills and potential of young people. His interviews are suffused with enthusiasm for his work in a holiday camp and for life in general: 
I like to do something different... I'm more of a people person really, I like to get there and chat to people, there's so many interesting people out there you know... I'm really lucky because I've got a residency in a nightclub in Weymouth and I'm working for them every Saturday evening and that's brilliant as well. (Rick)

While work may be important to the young people it only constitutes part of their lives. As one member of our participative seminar put it: 'they work to live not live to work'. Commenting on this, Ball et al. (2000) have noted:

... occupational status and work may not be that important in the lives of 'the young' ... Other sources of identity and identification deriving from music, fashion and leisure may be more central to how they think about themselves (Ball et al. 2000: 7).

We are not entirely comfortable with the typologies derived from Beck's (1992) distinction between 'choice' and 'normal' biographies largely because they are not sufficiently mindful of the impact of structure on the young people's life chances. Here commentators such as du Bois-Reymond (1998) and Wyn and Dwyer (1999) note a shift from 'normal' biographies experienced in the past, where young people typically moved into work or higher education in their teenage years (Ashton and Field, 1976), towards 'choice' and 'mixed patterns' where young people (particularly those in the middle-classes) have been able to postpone their work identities.

We live in a society where much of the onus is upon gaining school level qualifications, continuing in education, and on achieving a 'respectable job' with training (Skeggs 1997). This narrative ignores wider contextual issues and other issues that bear-upon young people's lives. Being vague on details, constructing a narrative to satisfy others (Wright Mills 1940), misunderstanding and 'refusing' to make a linear and coherent narrative represent different solutions to the problem facing young people (see also Lawy 2002a; 2006; Nayak 2006).

\section{(Mis)representation}


...each young person is different, even though they are seen to be in a job with no training - he is happy with this and content with his life. This will make me more aware ... so not to get caught up in the 'thought' that they should move on to get a better job. (PA journal)

One of the dangers of categorising young people as being in JWT is that the category itself reifies and constructs the very problem that it seeks to address. This immediately opens the possibility for misrepresentation. Almost all of the young people in our sample were white and working-class, using their parents' occupations as an indicator (Sveinsson 2009). They were from families where the opportunity to move and follow good or well resourced schools or pay for private education was not an option. Their accounts of secondary education were of large impersonal schools where bullying was rife and where they were quickly labelled as low achieving and in need of advice and guidance, with several participants referring to problems related to dyslexia and learning difficulties. Positioned as the 'thick bunch' and with such negative experiences to draw upon, the young people were keen to leave school and move on with their lives:

When I got to secondary school it all went downhill... it was just bullying and the teachers just chose to ignore us. The way I saw it in my experience is that they knew about the problem, they knew what was going on, they'd seen it happen and they did nothing about it. (Jo)

It is hardly surprising therefore that the young people were unprepared and unwilling to subject themselves to the formalised learning that they associated with schooling or with the labels of failure associated with it. They wanted to leave the past behind and make a fresh start. However, this did not lead to permanent stasis. During the period of the research we observed some quite dramatic changes in the young people as life commitments and experiences, sometimes in work but also outside, led them to begin to reappraise their options and aspirations:

It makes you realise that GCSEs and stuff really don't affect what you do outside, work-wise and dealing with real life situations, you realise there's a lot more stuff that's more important than grades. Getting a 
job really does depend on what sort of person you are and whether people can work with you. (Liz)

The young people in JWT that we interviewed were clearly more constrained and limited in terms of opportunity, than their middle-class counterparts in school and college; but this did not mean that they did not make choices or assess and take risks. Rather, they rationalised their actions and assessed risks in ways that were internal to them and to their experiences (Lawy 2002b; Douglas 1992). Jo, for example benefited from her working experience in Greece, returning as a much more confident young woman despite the long hours, very poor pay and abrupt termination of her contract:

Yeah just kind of grab the bull by the horns and just went for it. I thought well if I am going to be travelling you know why spend so much money, why not go somewhere for a longer amount of time, work earn my money, then I can go on from there. (Jo)

Jo did not travel abroad in the knowledge that she could return to a university or college course or that she could count on the financial support of her family. She was on her own in the world and her actions constituted a different category of risk. At the time of her second interview she had returned to her old supermarket job. The risk she took to work abroad had not succeeded in leading directly to a better-paid job, however the experience did increase her self-confidence and maturity and did cause her to consider her future career and prospects. Other young people in our sample were not prepared to tolerate what they saw as poor quality provision, preferring to leave work rather than continue, and were dismissive of the accredited courses provided by training providers to meet their skills needs:

I was doing the Customer Care thing one day a month [via Learning Agreement]. It was not like kosher it was like the whole place was set up for people who couldn't find jobs or had made themselves jobs, all the people who worked there were the sort of people who did. (Liz)

Whilst the majority of the young people did not wish to continue with formal study, since that represented a source of failure to many of them, it did not mean that they 
did not wish to learn or that they did not want access to learning opportunities. They valued being in the workplace rather than in the classroom since it made them more mature: 'because we've been out in the real world, we know more about what's going on' (Dick). The skills they needed in their work roles were not 'how-to-do' skills associated with particular tasks but were job related and inevitably involved learning 'softer' social skills. Many of the young people made distinctions between learning something they found valuable and needed for the job they were doing and training for the sake of training, which they saw as questionable:

[Q]uite a few [of my friends] are just doing random courses at college, they don't know what they want to do when they're older, they're just doing a course. I don't want to like just join a course in college because that would be a waste of time. (Fred)

Many, simply needed time to try out different options and become more mature before making their choices (Equal, Brighton and Hove 2008). Others wanted the opportunity to engage in other interests, Rick for example, explained how his Connexions PA had not only been able to organise practical support, such as buying a suit for work and placing advertisements in the local press, but also helped him think strategically about his career direction:

Coming here helped me out a lot ... I was a little bit at a dead end, so I came here and they put me on the right tracks... [my PA] taught me to get over hurdles, look at other scenarios that are there which you can't always see. So I've gone through different routes around things. (Rick)

Our findings support those of Green and White (2007) who have noted that young people's work opportunities and their attitudes to them are shaped by their social networks and attachments (see also Macdonald et al. 2005). Public transport services were frequently inadequate and consequently mobility and the capacity to take up employment or training were reduced. The regional makeup of our sample (comprising a large rural element) exacerbated these problems:

I had to take two buses to get there. (Tamara) 
I've got to figure out a way how to get there by 8.30 am tomorrow and there's no trains or buses that go directly there. (Liz)

The young people not only faced job market restrictions but employment opportunities that were limited and often seasonal, lacking job security, particularly in the seaside areas:

Oh yes a lot of tourists come down here, but it's not very busy the rest of the time,...they always try to get some extra staff then they're dismissed as soon as summer's over. (Jo)

They (the building work agency) said they doesn't want to keep me cos I was the last one on wasn't I? (Dave)

Despite these very real difficulties, all of the cohort presented themselves as making choices about their lives. None was unwilling to cede control of their lives to structural forces outside of their control. Such 'felt' agency (Lawy 2003), 'lends support to the notion of structured individualization' (Rudd and Evans 1998, 61 original emphasis) and the idea (despite evidence to the contrary) that the young people are in full control of their own destinies. This notion of control is a problematic one, as it could be argued that it is the very essence of neo-liberalism to present the individual as entirely responsible for their own destiny. However, we feel we cannot deny these young people their sense of agency, despite the fact that it is very evidently constrained by factors such as poverty and inequality.

Charmaine, for example was repeatedly thrown out of home and explained that she had managed on her own since adolescence. Despite these difficulties she was at pains not to blame others for her predicament. She presented herself as making choices about her life:

Don't ever think you are stuck in a dead-end because you can just pull yourself up. It's like people like on a world basis you could easily get onto heroin or something and think you are in a dead-end world but all 
they have to do is bring themselves up and see a psychiatric help and get themselves up and get a job. (Charmaine)

In this section we have demonstrated the limitations of tying debates about JWT to the rhetoric of work ethic or self-help or any other category without recognising that young people in JWT are no different to any other group of young people with lives embedded in 'history, biography and structure' (Heath et al. 2007, 12). We have seen that the judgements that young people made about themselves are very different than those used by policy makers whose understandings and solutions are framed in terms of social exclusion (Social Exclusion Unit 1999; Cabinet Office 2008), and their position in the labour market. The young people in our study did not simply view their lives in terms of their economic worth and employability. They had many interests which were represented in their identifications and identities. In this respect, claims and assumptions about the 'needs' of young people represent a performative function that is prior to and supersedes any claim to meaning-making and understanding by the young people themselves.

\section{Conclusions}

It was apparent almost from the outset of the research that we needed to reconceptualise or at least question many of the underlying assumptions about young people in JWT. We became conscious of the need for a more rounded, nuanced and substantiated evidence-base that valorises the experiences of young people themselves, to support the claims of policy makers about the needs interests and enthusiasms of young people. Whilst we recognised that this would not provide a direct or immediate solution to the problems facing this group of young people, we believed that a fuller understanding and representation of young people was an important first step in addressing the issues facing young people in JWT

One of the issues raised by the research was that the whole notion of JWT as a category is a construction or reification rather than something that is real. To put this another way, young people in JWT are only in that category because of the way that they are defined. But at the same time young people in this category are commonly elided with those who have been described as having 'Status Zero' (Rees et al. 1996) 
who are NEET. Indeed, there is an assumption, promulgated in media portrayals of them, that JWT is a deficit category with young people who are in some way different to their contemporaries who are undergoing formal training or are undertaking fulltime study. This negative stereotyping and the labels attached to them have served not only to define them (Matza 1969) but also to locate them within particular narrative frameworks.

As a result of the interviews with the young people the research team, and this included the PAs who conducted the telephone interviews, was 'forced' to reconsider and in many instances reconstruct its views of young people in JWT. Our picture of JWT was not one of homogeneity but of heterogeneity and difference. The young people in our study were not 'dopes' or inadequate, rather they were active coconstructors of their lives, asserting degrees of agency and control over different aspects of their lives including their self-identifications and presentations. Notwithstanding this, we were conscious of the danger of romanticising the experiences of this group of young people, who are structurally disadvantaged in terms of 'opportunity structures' (Roberts 1968) - housing and schooling and in terms of their access to training and work. This is particularly the case at a time when there is mounting evidence of rising rates of youth unemployment (January 2009).

Lack of knowledge and understanding about the broader lives of the young people and a set of largely unresearched views about their needs, misrepresents them and is founded upon simplistic and naïve (but also potentially dangerous) assumptions about them. Certainly the young people that we interviewed were not work-shy, although they did not necessarily see the value of achieving formal qualifications, preferring instead to learn credible job-related skills including 'soft' social skills that are important in workplace cultures as an important prerequisite and entrée into workbased communities of practice (Lave and Wenger 1991).

We were able to see that the relative stability of the JWT numbers masked a great deal of internal fluidity within the category. The trajectories of the young people did not comprise linear pathways, rather the young people moved almost routinely into and out of employment. $18 \%$ of our sample moved out of the JWT category into formalised training and $17 \%$ slipped into NEET during the period of the research, 
which represents a turnover of $35 \%$. Within our qualitative data, we found strong evidence of the desire of the young people to be employed, which directly contradicts claims that these young people are feckless, lazy and unwilling to work. What was interesting was that the reasons given by the young people for working did not accord to the largely economistic and folk theories of employment that assume they will act in a technical rational manner to maximise their economic potential (Hodkinson, et al. 1996). As Cohen and Ainley (2000) argue:

The youth-as-transition approach not only implies a linear teleological model of psychological development, it is premised upon the availability of waged labour as the 'ultimate goal'. The consequent emphasis on production has led to a limited research paradigm focused on 'transition' as a rite of passage between the states of psychological maturity and immaturity. (p. 80)

The young people in our study shared much in common with their contemporaries, in terms of their values and aspirations. Many, for example, secured employment via informal contacts and social networks. A minority had informal skills and interests and were able to develop them into career paths but for the most part, they do not have access to the social networks to do this as effectively as their more middle-class counterparts. Moreover, they did not seek to blame others for the conditions of their lives and were keen to claim responsibility for their own decisions and actions. We would agree with Rudd and Evans who argue that despite evidence to the contrary:

[A] young person will typically be optimistic and will say he or she is in control of his or her life course and that occupational success is largely based on individual effort .. (Rudd and Evans 1998: 41 original emphasis)

As we have argued, this optimism may actually serve to hide the structural problems that they face and thus serves to perpetuate rather than fight against inequalities.

The young people sometimes found it difficult to construct coherent self-narratives to justify their actions, while others drew upon extant 'vocabularies of motive' (Wright 
Mills 1940) in order to explain their actions to others. By so doing they were able to continue with their own lives, whilst managing their relations with outsiders. Our research allowed us to listen to young people, to understand how they imagine their lives, and construct a fuller and more nuanced picture of their lives in the here and now. Work was important to them, providing a focus for their day-to-day activities, and an identity that allowed them to draw meaning from their lives. However, it was not the only source of identity, they did not 'live to work' and were able to fashion identities and draw meaning from different dimensions of their lives outside of work. Such representations are commonly overlooked or discounted, with the mass media, politicians and others drawing upon a well-rehearsed narrative that assumes that young people speak with one particular voice (Anderson et al. 2006).

We have argued that young people have been misunderstood and misrepresented and that what is needed is research to uncover more about the lives and interests of this socially disadvantaged and excluded group. Lack of knowledge and understanding about the broader lives of young people in JWT, combined with a set of largely unresearched assumptions about their needs, has contributed to policy decisions that are founded upon a set of naïve and misplaced assumptions about them. These policy decisions enshrine a neo-liberal view that work is the key to identity, but only certain kinds of 'respectable' work. This viewpoint essentially cancels out the lives of these young people. 


\section{References}

Aldridge, F., and Tuckett, A. 2007. The road to nowhere? NIACE survey on adult participation. Leicester: NIACE.

Anderson, A., Brooke, B., Doyle, A., Finn, D. and Moley S. 2006. Understanding young people in jobs without training. Research Report 736. London: DfES.

Ashton, D. and Field, D. 1976. Young workers: From school to work. London: Hutchinson.

Avis, J. 1996. The myth of the post-Fordist society. In Knowledge and nationhood: education, politics and work, ed. J. Avis, M. Bloomer, G. Esland, D. Gleeson, and P. Hodkinson., 71-82. London: Cassell.

Ball, S.J., Macrae, S. and Maguire, M. 1999. Young lives, diverse choices and imagined futures in an education and training market, International Journal of Inclusive Education 3 no. 3: 195-224.

Ball, S. J., Maguire, M. and Macrae, S. 2000. Choice, pathways and transitions post16: new youth, new economies in the global city. London: Routledge Falmer.

Beck, U. and Beck-Gernsheim, E. 1992. Individualization. London: Sage.

Bynner, J. and Parsons, S. 2002. Social exclusion and the transition from school to work: the case of young people not in education, employment, or training (NEET), Journal of Vocational Behavior 60: 289-309.

Cabinet Office. 2008. Life chances: supporting people to get on in the labour market. an analytical discussion paper. Available online at: http://www.dius.gov.uk/publications/life_chances_180308.pdf (accessed 16 Oct 2008). 
Cohen, P. and Ainley, P. 2000. In the country of the blind?: Youth studies and cultural studies in Britain. Journal of Youth Studies 3, no. 1: 79-95.

Cole, M. 2007. Re-thinking unemployment: a challenge to the legacy of Jahoda et al. Sociology 41, no. 6: 1133-1149.

Connexions 2005. Moving on-2005: Pathways taken by young people beyond 16: Annual activity survey 2005. London: DfES.

Department for Education and Employment (DfEE) 1998 Young people in jobs without training. Research brief no. 75, IFF Ltd., ISBN 0855228342.

Department for Education and Skills (DfES) (2006) Participation in education, training and employment by 16-18 year olds in England: 2004 and 2005. SFR 21/2006. London: DfES.

Department for Education and Skills (DfES) 2007. [Green Paper] Raising Expectations: Staying in education and training post 16. London: DfES.

Douglas, M. 1992. Risk and blame: Essays in cultural theory. London: Routledge.

Du Bois-Reymond, M. 1998. 'I don't want to commit myself yet': Young people's life concepts. Journal of Youth Studies 1 no.1: 63-80.

Equal, Brighton and Hove 2008. Available online at: http://www.equalbrightonandhove.org/node/369 (accessed 03/01/08).

Furlong, A. and Cartmel, F. 1997. Young people and social change: Individualization and risk in late modernity. Buckingham: Open University.

Giddens, A. 1991. Modernity and self-identity: Self and society in the late modern age. Cambridge: Polity. 
Golby, M. 1994. Case study as educational research. (Research Support Unit: University of Exeter.

Goodwin, J. and O'Connor, H. 2007. Continuity and change in the experiences of transition from school to work. International Journal of Lifelong Education 26, no. 5: $555-572$.

Green, A. E. and White, R. J. 2007. Attachment to Place: Social networks, mobility and prospects of young people. York: Joseph Rowntree.

Hayward, G., Hodgson, A., Johnson, J., Keep, E., Oancea, A., Pring, R., Spours, K., Wright, S. and Wilde, S. 2006. Annual Report of the Nuffield 14-19 review 2005-6. Oxford: University of Oxford.

Heath, S., Fuller, A. and Paton, K 2007. Life course, generation and educational decision - making within networks of intimacy. Paper presented at BERA Annual Conference 6-8 September.

Hodgson, A. and Spours, K. 2007. Specialised diplomas: Transforming the 14-19 landscape in England? Journal of Education Policy 22, no. 6: 657-673.

Hodkinson, P., Sparkes, A.C. and Hodkinson, H. 1996. Young people, markets and the transition from school to work. London: David Fulton.

Huddleston, P. and Maguire, S. 2008. Young People in 'Jobs without Training': What are they really doing? Paper presented at: Illuminating the Hidden World of Vocational Learning and Post-School Transitions, Conference. Institute of Education, London, February 28.

Hughes, E. 1937. Institutional office and the person. American Journal of Sociology. 43, no.3: 403-413.

Jahoda, M. 1982. Employment and unemployment: A social-psychological analysis. Cambridge: Cambridge University Press. 
Lave, J. and Wenger, E. 1991. Situated learning: Legitimate peripheral participation. Cambridge: Cambridge University Press.

Lawy, R. 2002a. Transition and transformation: The experiences of two young people. Journal of Education and Work 15, no. 2: 201-218.

Lawy, R. 2002b. Risky stories: Youth identities, learning and everyday risk. Journal of Youth Studies 5, no.4: 407-423.

Lawy, R. 2003. Transformation of person, identity and understanding: A case study. British Journal of Sociology of Education 24, no.3: 331-345.

Lawy, R. 2006. Connective learning: Young people's identity and knowledge-making in work and non-work contexts. British Journal of Sociology of Education 27, no.3: 325-340.

Lawy, R., Quinn, J. and Diment, K. 2008 [working paper] Responding to the 'Needs' of young people in jobs without training (JWT): Some policy suggestions and recommendations. Exeter: University of Exeter.

Leitch. S. 2006. Leitch. Review of skills prosperity for all in the global economyworld class skills. London: HMSO.

MacDonald, R., Shildrick, T., Webster, C., Johnston, L. and Ridley, L. 2005. Growing up in poor neighbourhoods: The significance of class and place in the extended transitions of 'socially excluded' young adults. Sociology, 39, no. 5: 873-891.

Maguire, S. and Rennison, J. 2005. Two years on: The destinations of young people who are not in education, employment or training at 16. Journal of Youth Studies 8, no.2: 187-201.

Matza, D. 1969. Becoming deviant. London: Prentice Hall. 
Nayak, A. (2006) Displaced masculinities: Chavs, youth and class in the postindustrial city. Sociology 40, no.5: 813-831.

Nuffield Review of 14-19 Education and Training. 2008. EYE briefing paper 3. Rates of post-16 non-participation in England. Available online at: http://www.nuffield1419review.org.uk/files/documents195-1.pdf (accessed 2 January 2009).

Nash, I. 2007. Employers turn backs on skills. Times Educational Supplement, 18 May. Available online at: www.tes.co.uk (accessed 5 September 2007).

Office for National Statistics 2005a. Youth Cohort Study: The activities and experiences of 16 year olds: England and Wales 2004, SFR 04/2005. London: DfES.

Office for National Statistics 2005b. Labour force survey historical quarterly supplement: Calendar quarters. London: DfES.

Office for National Statistics 2006. Youth cohort study: The activities and experiences of 18 year olds: England and Wales 2006, SFR 47/2006. London: DfES.

Organisation for Economic Co-operation and Development. 2006. Education at a glance 2006, OECD indicators. Paris: OECD.

Organisation for Economic Co-operation and Development. 2007. Education at a glance 2007, OECD indicators. Paris: OECD.

Quinn, J., Lawy, R. and Diment, K. 2008a 'Dead-end kids in dead-end jobs'? Reshaping debates on young people in jobs without training. Research in PostCompulsory Education 13, no. 2: 185-194.

Quinn, J., Lawy, R. and Diment, K. 2008b. Young people in jobs without training in South West England: Not just 'dead-end kids in dead-end jobs'. University of Exeter: SLIM. 
Quinn, J., Thomas, L., Slack, K., Casey, L., Thexton, W, and Noble, J. 2006. Lifting the hood: Lifelong learning and young white provincial working class masculinities. British Educational Research Journal 32, no.5: 735-751.

Rees, G., Williamson, H. and Istance, D. 1996. 'Status Zero': A study of jobless school-leavers in South Wales. Research Papers in Education 11, no.2: 219-235.

Ribbens-McCarthy, J., Edwards, R. and Gillies, V. 2002. Making families. York: Sociology Press.

Roberts, K. 1968. The entry into employment: an approach towards a general theory. Sociological Review, 16(2), 165-184.

Rudd, P. and Evans, K. 1998. Structure and agency in youth transitions: Student experiences of vocational further education, Journal of Youth Studies 1, no.1: 39-62.

Skeggs, B. 1997. Formations of class and gender: Becoming respectable. London: Sage.

Skeggs, B. 2004. Class, self, culture. London: Routledge.

Social Exclusion Unit (SEU) (1999) Bridging the gap: New opportunities for 16-18 year olds not in education, employment or training. London: Stationery Office.

Sveinsson, K. P. (ed) .2009. Who cares about the white working class? London: Runnymede Trust.

Weber, M. 1964. The theory of social and economic organization. New York: Free Press.

Yates, S. and Payne, M. 2006. Not so NEET? A critique of the use of 'NEET' in setting targets for interventions with young people. Journal of Youth Studies 9, no.3: 329-344. 
Wright Mills, C. 1940. Situated actions and vocabularies of motive. American Sociological Review 5, no.6: 904-913.

Wyn, J. and Dwyer, P 1999. New directions in research on youth in transition. Journal of Youth Studies 2, no. 1: 5-21.

[8009 words] 